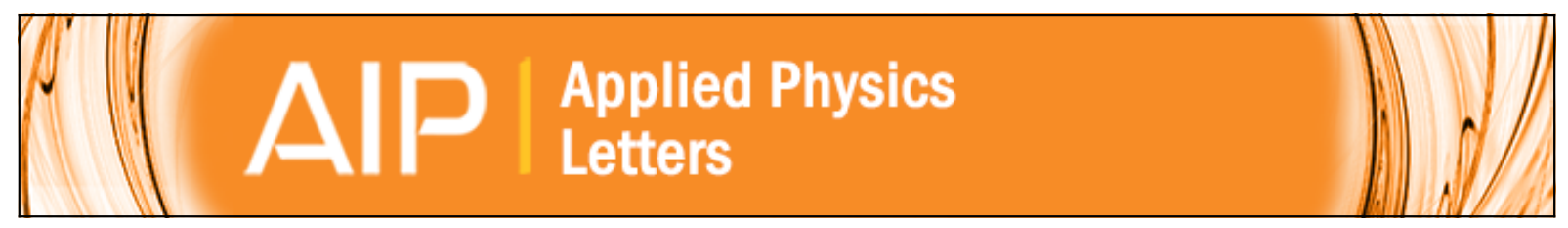

Fatigue-free behavior of $\mathrm{Bi} 3.25 \mathrm{La} 0.75 \mathrm{Ti} 3 \mathrm{O} 12$ thin films grown on several bottom eletrodes by the polymeric precursor method

A. Z. Simões, A. Ries, F. M. Filho, C. S. Riccardi, J. A. Varela, and E. Longo

Citation: Applied Physics Letters 85, 5962 (2004); doi: 10.1063/1.1834999

View online: http://dx.doi.org/10.1063/1.1834999

View Table of Contents: http://scitation.aip.org/content/aip/journal/apl/85/24?ver=pdfcov

Published by the AIP Publishing

Alp Pe-register for Table of Content Alerts

Create a profile. 


\title{
Fatigue-free behavior of $\mathrm{Bi}_{3.25} \mathrm{La}_{0.75} \mathrm{Ti}_{3} \mathrm{O}_{12}$ thin films grown on several bottom eletrodes by the polymeric precursor method
}

\author{
A. Z. Simões, ${ }^{\text {a) }}$ A. Ries, F. M. Filho, C. S. Riccardi, and J. A. Varela \\ Chemistry Institute, UNESP_Paulista State University, C.P. 355, 14801-970 Araraquara, SP, Brazil \\ E. Longo \\ Chemistry Department, UFSCar - Federal University of São Carlos, C.P. 676, 13560-905 São Carlos, \\ SP, Brazil
}

(Received 1 June 2004; accepted 26 October 2004)

\begin{abstract}
Fatigue-free $\mathrm{Bi}_{3.25} \mathrm{La}_{0.75} \mathrm{Ti}_{3} \mathrm{O}_{12}$ (BLT) thin films were grown on $\mathrm{LaNiO}_{3}, \mathrm{RuO}_{2}$, and $\mathrm{La}_{0.5} \mathrm{Sr}_{0.5} \mathrm{CoO}_{3}$ bottom electrodes in a microwave furnace at $700{ }^{\circ} \mathrm{C}$ for $10 \mathrm{~min}$. The remanent polarization $\left(P_{r}\right)$ and the drive voltage $\left(V_{c}\right)$ were in the range of $11-23 \mu \mathrm{C} / \mathrm{cm}^{2}$ and $0.86-1.56 \mathrm{~V}$, respectively, and are better than the values found in the literature. The BLT capacitors did not show any significant fatigue up to $10^{10} \mathrm{read} /$ write switching cycles. (C) 2004 American Institute of Physics. [DOI: $10.1063 / 1.1834999]$
\end{abstract}

As a fatigue-free material, $\mathrm{Bi}_{3.25} \mathrm{La}_{0.75} \mathrm{Ti}_{3} \mathrm{O}_{12}$ (BLT) is of particular interest because it can be crystallized at relatively low processing temperatures close to $650^{\circ} \mathrm{C}$. Fatigue-free BLT films have been grown on $\mathrm{Pt} / \mathrm{Ti} / \mathrm{SiO}_{2} / \mathrm{Si}$ substrates. However, a possible interfacial reaction between platinum and bismuth can lead to undesired electrical properties. Therefore, the substitution of metallic electrodes based on noble metals, such as platinum by conductive oxides is an alternative to reach better electrical properties caused by the high oxygen affinity of these electrodes. ${ }^{1}$ For this purpose, it is interesting to evaluate the properties of BLT films deposited on electrodes based on metallic oxides, such as $\mathrm{LaNiO}_{3}, \mathrm{La}_{0.5} \mathrm{Sr}_{0.5} \mathrm{CoO}_{3}$, and $\mathrm{RuO}_{2}$.

Several attempts have been made to enhance the crystallization ability of ferroelectric thin films and metallic oxide electrodes. ${ }^{2,3}$ Recently, the use of a domestic microwave furnace has been developed as a way to process materials and has opened an opportunity to enhance crystallization with a lower annealing processing time since it decreases the interfacial reactions between ferroelectric thin films and electrodes and also improves the control over the crystallographic orientation of the thin films. ${ }^{4}$

Among various methods, such as metalorganic chemical vapor deposition, pulse laser deposition, and sol gel, the polymeric precursor method has a better potential for technological applications, because of their precise control of composition and homogeneity and good conformality. ${ }^{5}$ In the present work, we present the preparation of BLT films on the metallic oxides with excellent structural, microstructural, and electrical properties by the polymeric precursor method.

The $\mathrm{LaNiO}_{3}, \mathrm{La}_{0.5} \mathrm{Sr}_{0.5} \mathrm{CoO}_{3}, \mathrm{RuO}_{2}$, and BLT thin films were prepared the polymeric precursor method, as described elsewhere. ${ }^{5}$ The bottom electrodes thin films were spin coated on (100) $\mathrm{Si} / \mathrm{SiO}_{2}$ substrates by a commercial spinner operating at 5,000 revolutions/min for $30 \mathrm{~s}$ (spin coater KW4B, Chemat Technology). Each annealing layer was prefired at $400{ }^{\circ} \mathrm{C}$ for $2 \mathrm{~h}$ in a conventional oven. After the prefiring, each layer was crystallized in a microwave oven at $700{ }^{\circ} \mathrm{C}$ for $10 \mathrm{~min}$. Using the same procedure, the BLT thin films were deposited by spinning the precursor solution on the

${ }^{a)}$ Electronic mail: alezipo@yahoo.com desired substrates. Through this process, we have obtained thickness values of about $150 \mathrm{~nm}$ for the bottom electrodes and around $300 \mathrm{~nm}$ for BLT, reached by repeating the spincoating and heating treatment cycles. Phase analysis of the films were performed at room temperature by $x$-ray diffraction (XRD) using a Bragg-Brentano diffractometer (Rigaku $2000)$ and $\mathrm{Cu} K \alpha$ radiation. The morphology and the thickness of the films were examined using atomic force microscopy (AFM) (Digital Instruments, Nanoscope IIIa) and scanning electron microscopy (Topcom SM-300), respectively. The electric properties were measured by an $\mathrm{Au} / \mathrm{BLT} / \mathrm{LaNiO}_{3} / \mathrm{La}_{0.5} \mathrm{Sr}_{0.5} \mathrm{CoO}_{3} / \mathrm{RuO}_{2} / \mathrm{SiO}_{2} / \mathrm{Si}$ (100) capacitor structure. Dielectric and ferroelectric properties of the capacitor were measured by an HP4192A impedance/gain phase analyzer and a Radiant Technology RT6000 A.

Figure 1 shows the XRD results for BLT films deposited on different bottom electrodes. All films consisted of a single phase of bismuth layered structure showing preferred (001) and (117) orientations. The XRD results clearly show that films deposited on the $\mathrm{La}_{0.5} \mathrm{Sr}_{0.5} \mathrm{CoO}_{3}$ electrode favor the growth of (117)-oriented grains, whereas in films deposited on $\mathrm{LaNiO}_{3}$ and $\mathrm{RuO}_{2}$ the growth of (001)-oriented grains dominated. According to Takenaka et al., ${ }^{6}$ for lanthanum contents higher than 0.50 the orthorhombicity of the struc-

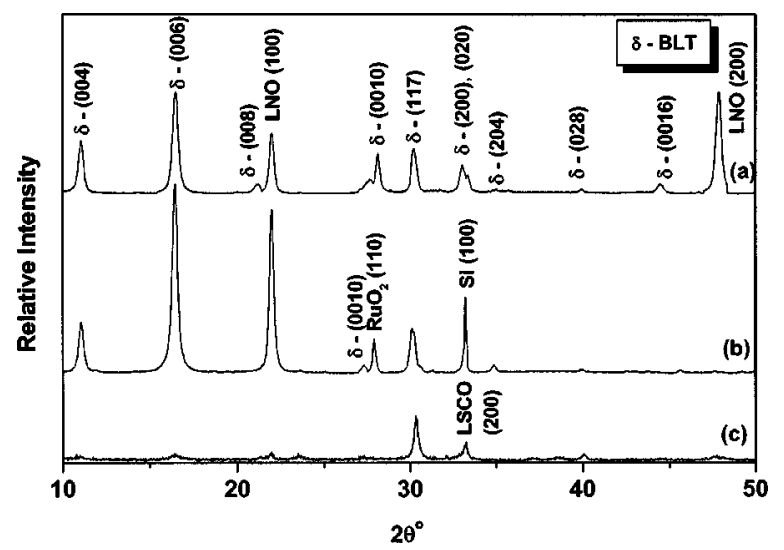

FIG. 1. XRD for $\mathrm{Bi}_{4-x} \mathrm{La}_{x} \mathrm{Ti}_{3} \mathrm{O}_{12}$ films $(x=0.75)$ deposited on different bottom electrodes at $700{ }^{\circ} \mathrm{C}$ for $10 \mathrm{~min}$ (a) $\mathrm{LaNiO}_{3}$, (b) $\mathrm{RuO}_{2}$, and (c) $\mathrm{La}_{0.5} \mathrm{Sr}_{0.5} \mathrm{CoO}_{3}$. 
TABLE I. Data obtained for $\mathrm{Bi}_{4-x} \mathrm{La}_{x} \mathrm{Ti}_{3} \mathrm{O}_{12}$ films $(x=0.75)$ deposited on different bottom electrodes at $700{ }^{\circ} \mathrm{C}$ for 10 min (a) $\mathrm{LaNiO}_{3}$, (b) $\mathrm{RuO} \mathrm{O}_{2}$ and (c) $\mathrm{La}_{0.5} \mathrm{Sr}_{0.5} \mathrm{CoO}_{3}$.

\begin{tabular}{|c|c|c|c|c|c|c|c|c|}
\hline Electrodes & $\begin{array}{c}P_{r} \\
\left(\mu \mathrm{C} / \mathrm{cm}^{2}\right)\end{array}$ & $\begin{array}{c}V_{c} \\
(\mathrm{~V})\end{array}$ & $\begin{array}{c}\epsilon \\
(1 \mathrm{MHz})\end{array}$ & $\begin{array}{c}\tan \delta \\
(1 \mathrm{MHz})\end{array}$ & $\begin{array}{l}\text { Roughness } \\
\quad(\mathrm{nm})\end{array}$ & $\begin{array}{l}\text { Average grain size } \\
\quad(\mathrm{nm}) \pm 1 \%\end{array}$ & $\begin{array}{c}J(1 \mathrm{~V}) \\
\left(\mu \mathrm{A} / \mathrm{cm}^{2}\right)\end{array}$ & $\begin{array}{c}\text { Thickness } \\
(\mathrm{nm})\end{array}$ \\
\hline $\mathrm{LaNiO}_{3}{ }^{\mathrm{a}}$ & 11.4 & 1.26 & 176 & 0.047 & 4.4 & 81 & 4.3 & 283 \\
\hline $\mathrm{RuO}_{2}^{\mathrm{a}}$ & 16.7 & 1.56 & 160 & 0.019 & 4.3 & 58 & 2.2 & 270 \\
\hline $\mathrm{La}_{0.5} \mathrm{Sr}_{0.5} \mathrm{CoO}_{3}{ }^{\mathrm{a}}$ & 23.1 & 0.84 & 182 & 0.012 & 7.5 & 65 & 0.4 & 305 \\
\hline $\mathrm{SrRuO}_{3}{ }^{\mathrm{b}}$ & 10.2 & 3.60 & $\cdots$ & $\cdots$ & $\cdots$ & $\cdots$ & $\cdots$ & 300 \\
\hline $\mathrm{Pt} / \mathrm{Ti} / \mathrm{SiO}_{2} / \mathrm{Si}^{\mathrm{c}}$ & 10.0 & $\cdots$ & 220 & 0.01 & $\cdots$ & $\cdots$ & $\cdots$ & $\cdots$ \\
\hline $\mathrm{LaNiO}_{3}{ }^{\mathrm{d}}$ & 8.0 & 1.92 & 128 & 0.024 & $\ldots$ & $\cdots$ & 0.1 & 240 \\
\hline $\mathrm{Pt} / \mathrm{Ti} / \mathrm{SiO}_{2} / \mathrm{Si}^{\mathrm{e}}$ & 11.4 & 2.22 & 260 & 0.028 & $\cdots$ & $\cdots$ & $\ldots$ & $\cdots$ \\
\hline
\end{tabular}

${ }^{\mathrm{b}}$ Ref. 15 .

${ }^{\mathrm{c}}$ Ref. 10.

${ }^{\mathrm{d}}$ Ref. 13. ture decreases. This structural distortion might be responsible for the unsual electrical properties of the BLT system. The here discussed preferred orientations can be caused by differences in lattice parameters and thermal expansion coefficients for different oxide electrodes and indicate that the polar axis is closer to (117) than (001). AFM studies (not shown) revealed that, independent of the electrode used, a homogeneous surface was observed indicating that the microwave furnace allows the preparation of films with controlled morphology. The average surface roughness value is in the range from 4.3 to $7.5 \mathrm{~nm}$ while the average grain size is in the range from 58 to $85 \mathrm{~nm}$ (Table I).

Ferroelectricity of the lanthanum-doped bismuth titanate thin films was observed independently of the bottom electrode used (Fig. 2). However, for the films deposited on the $\mathrm{LaNiO}_{3}$ and $\mathrm{RuO}_{2}$ electrodes the trapped charge $\left(\mathrm{O}_{2}^{\prime}\right)$ associated with other defects $\left(V_{0}{ }^{*}\right)$ or even defect dipole complexes, such as oxygen vacancies associated with bismuth vacancies $\left(V^{\prime \prime \prime}{ }_{B i}-V_{0}{ }^{*}\right)$ located in the grain boundary and in film-electrode interface can promote a local stoichiometry deviation influencing the shape of the hysteresis loops. As a consequence of these space charges, a significant shift along the electric-field axis toward the positive side, which is defined as an imprint, may lead to a failure of the capacitor. A more symmetric hysteresis loop is observed for the film deposited on $\mathrm{La}_{0.5} \mathrm{Sr}_{0.5} \mathrm{CoO}_{3}$ electrode indicating that the high oxygen affinity of this material avoids the migration of charge species to the electrode-film interface. This behavior can be ascribed to the platelike grains of the BLT films (not shown as a figure). The domain walls in platelike grains are easier to be switched under an external field. Similar phenomena have been found in SBT and PT thin films. ${ }^{7,8}$ Therefore, the growth of the film in one direction not coincident to $c$-axis preferred orientation will favor the platelike morphology, such as the ones grown on $\mathrm{La}_{0.5} \mathrm{Sr}_{0.5} \mathrm{CoO}_{3}$ oxide electrode leading to a lower $E_{c}$ when compared to those grown on $\mathrm{LaNiO}_{3}$ and $\mathrm{RuO}_{2}$ electrodes. Comparing the BLT thin films deposited on several bottom electrodes and obtained from different methods, the polymeric precursor method combined with the microwave processing allows the preparation of films with high dielectric and ferroelectric properties, as can be seen in Table I. The inset in Fig. 2 illustrates the Capacitance-voltage $(\mathrm{C}-\mathrm{V})$ curves for BLT films obtained at $100 \mathrm{kHz}$ and dc sweep voltage from +10 to $-10 \mathrm{~V}$. The capacitance dependence on the voltage is strongly nonlinear, confirming the ferroelectric properties of the film resulting from the domain switching. The $C-V$ curve for the film deposited on a $\mathrm{La}_{0.5} \mathrm{Sr}_{0.5} \mathrm{CoO}_{3}$ electrode is symmetric around the zero-bias axis, indicating that the films contain few movable ions or charge accumulation at the film-

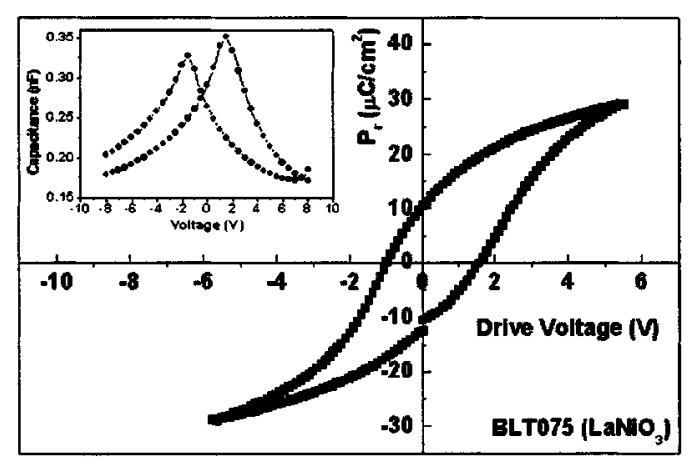

(a)

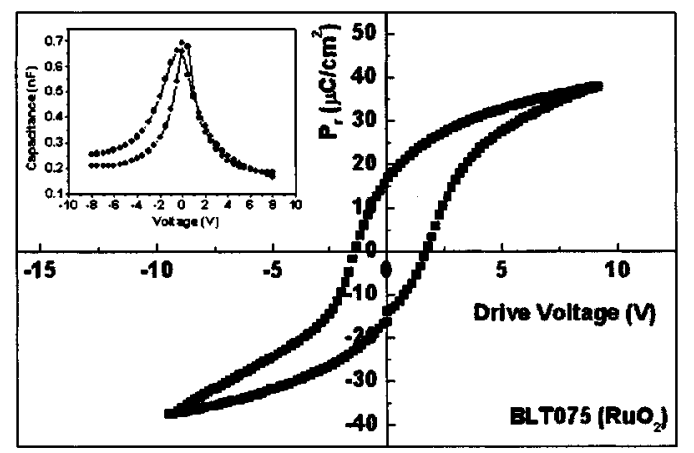

(b)

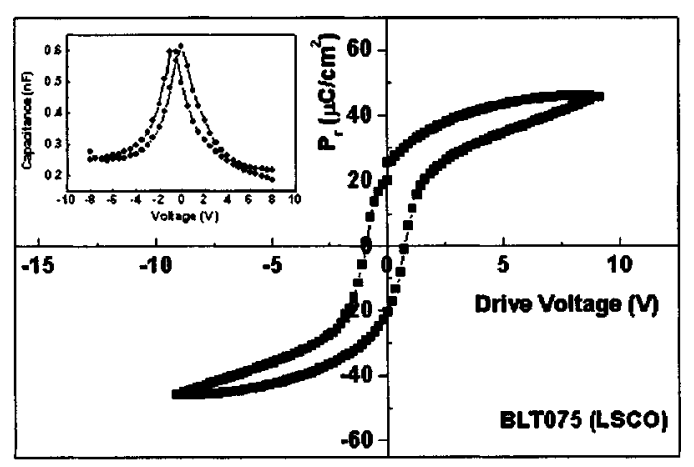

(c)

FIG. 2. P-E hysteresis loops for $\mathrm{Bi}_{4-x} \mathrm{La}_{x} \mathrm{Ti}_{3} \mathrm{O}_{12}$ films $(x=0.75)$ deposited on different bottom electrodes at $700{ }^{\circ} \mathrm{C}$ for $10 \mathrm{~min}$ (a) $\mathrm{LaNiO}_{3}$, (b) $\mathrm{RuO}_{2}$, and (c) $\mathrm{La}_{0.5} \mathrm{Sr}_{0.5} \mathrm{CoO}_{3}$. Inset of $C-V$ curves for $\mathrm{Bi}_{4-x} \mathrm{La}_{x} \mathrm{Ti}_{3} \mathrm{O}_{12}$ films $(x$ $=0.75$ ) deposited on different bottom electrodes at $700^{\circ} \mathrm{C}$ for $10 \mathrm{~min}$ (a) $\mathrm{LaNiO}_{3}$, (b) $\mathrm{RuO}_{2}$, and (c) $\mathrm{La}_{0.5} \mathrm{Sr}_{0.5} \mathrm{CoO}_{3}$. 


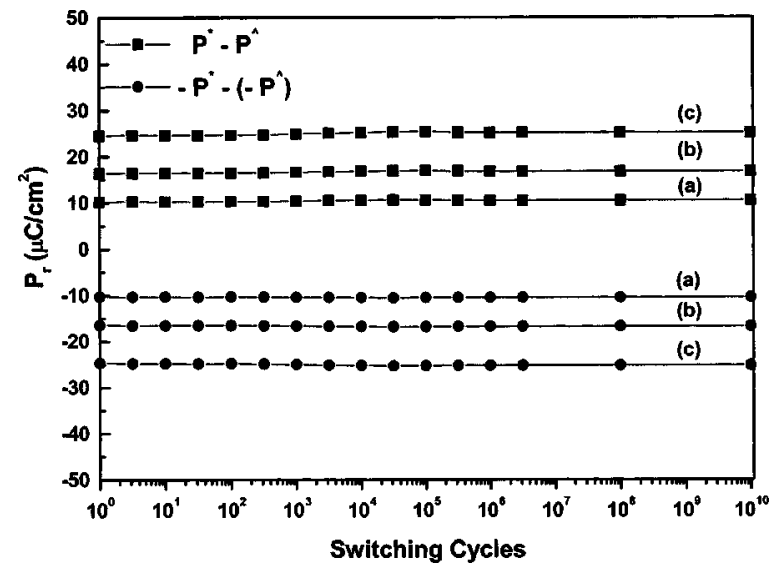

FIG. 3. Fatigue as a function of polarization cycles for $\mathrm{Bi}_{4-x} \mathrm{La}_{x} \mathrm{Ti}_{3} \mathrm{O}_{12}$ films $(x=0.75)$ deposited on different bottom electrodes at $700{ }^{\circ} \mathrm{C}$ for $10 \mathrm{~min}$ (a) $\mathrm{LaNiO}_{3}$, (b) $\mathrm{RuO}_{2}$, and (c) $\mathrm{La}_{0.5} \mathrm{Sr}_{0.5} \mathrm{CoO}_{3}$.

electrode interface. For films deposited on $\mathrm{LaNiO}_{3}$ and $\mathrm{RuO}_{2}$, a slight change in capacitance values is observed indicating the existence of charge carriers (oxygen vacancies) trapped near the film-electrode interface. These charges may originate during the heat treatment process due to the decomposition of the polymeric precursor. ${ }^{9}$ The narrowing of the $C-V$ curves obtained for the films deposited on $\mathrm{RuO}_{2}$ and $\mathrm{La}_{0.5} \mathrm{Sr}_{0.5} \mathrm{CoO}_{3}$ electrodes indicates that the process to switch the domains is faster in these electrodes and the saturation occurs with low energy for the ferroelectric domain alignment.

The insulating properties of the films were found to be dependent on the bottom electrode (Table I). The leakage current density decreased for the films deposited on the $\mathrm{La}_{0.5} \mathrm{Sr}_{0.5} \mathrm{CoO}_{3}$ electrode. Such a reduction in leakage current density may be attributed to a high oxygen affinity of the $\mathrm{La}_{0.5} \mathrm{Sr}_{0.5} \mathrm{CoO}_{3}$ electrode avoiding that oxygen in the electrode material will be depleted by the ferroelectric material, thus leaving an oxygen deficient layer of the electrode at the interface and increasing the contact resistance. From this study, it can be demonstrated that the microstructures of ferroelectric films play an important role in their conductivity properties. ${ }^{12}$ Comparing with literature data, our films present a higher leakage current than the films obtained on highly oriented $\mathrm{LaNiO}_{3}$-buffered $\mathrm{Pt} / \mathrm{Ti} / \mathrm{SiO}_{2} / \mathrm{Si}$ substrates by sol-gel process. ${ }^{13}$ Since the conductivity is strongly affected by the characteristics of the film-electrode interface, the lower leakage current observed in the literature may be attributed probably to differences in grain size, density, and preferred orientation due to differences in the metalferroelectric-metal configuration. Besides that, normally thin films on oxide electrodes exhibit higher leakage current in comparison to metal electrodes. ${ }^{14}$

Figure 3 presents the fatigue endurance of BLT thin films as a function of switching cycles. Fatigue resistance was observed up to $10^{10}$ cycles for all electrode oxides utilized in this study. The substitution of La for Bi can change the chemical environment of the perovskite layers and solve the fatigue problem of pure BLT thin films. Since $\mathrm{a} \mathrm{La}^{3+}$ ion has no outer electron, in contrast to a $\mathrm{Bi}^{3+}$ ion, which has a lone pair of $6 s$ electrons, less hybridization with $\mathrm{O} 2 p$ should lead to less structural distortion. ${ }^{15,16}$ As a consequence, the in-plane lattice constant, $a$, decreases while $b$ increases as $\mathrm{La}$ is substituted, resulting in a decrease in the orthorhombicity suggesting that the relaxation of the structural distortion arises from the substitution. However, the addition of $\mathrm{La}$ reduces the polarization along the $a$ axis leading to a significant decrease in the ferroelectric polarization when compared to pure BLT films. Since all oxide electrodes, such as $\mathrm{RuO}_{2}, \mathrm{La}_{0.5} \mathrm{Sr}_{0.5} \mathrm{CoO}_{3}$, and $\mathrm{LaNiO}_{3}$, result in fatigue-free films [Figs. 3(a)-3(c)], it is consequently, one may believe that if an oxygen vacancy accumulation near the filmelectrode interface occurs during fatigue, the conductive oxide can consume the oxygen vacancies by changing their oxygen nonstoichiometry and thus, the accumulation of oxygen vacancies near the interface is prevented or reduced. In conclusion, BLT thin films were obtained on $\mathrm{LaNiO}_{3}, \mathrm{RuO}_{2}$, and $\mathrm{La}_{0.5} \mathrm{Sr}_{0.5} \mathrm{CoO}_{3}$ electrodes from a polymeric solution and annealed by a microwave oven process through the spincoating technique. A regularly shaped hysteresis loop is observed for the films deposited on the $\mathrm{La}_{0.5} \mathrm{Sr}_{0.5} \mathrm{CoO}_{3}$ electrode due to the high oxygen affinity which avoids the migration of charge species for the electrode-film interface. High fatigue resistance was observed for films deposited on $\mathrm{LaNiO}_{3}, \mathrm{RuO}_{2}$, and $\mathrm{La}_{0.5} \mathrm{Sr}_{0.5} \mathrm{CoO}_{3}$ electrodes which proves that our films possess enough quality to be used in nonvolatile random access memories. However, due to the imprint phenomenon, the films deposited on $\mathrm{LaNiO}_{3}$ and $\mathrm{RuO}_{2}$ electrodes are unsuitable for memory applications as a consequence of the substantial difference between $+\mathrm{V}_{c}$ and $-\mathrm{V}_{c}$. Moreover, the polymeric precursor method combined with annealing in a microwave oven is an alternative approach to obtaining excellent BLT thin films and bottom electrodes. A remarkable improvement in the remanent polarization and drive voltage suggests that BLT thin films deposited on a LSCO oxide electrode are suitable for integrated device applications and can be used for ferroelectric random acess memories.

The authors gratefully acknowledge the financial support of the Brazilian agencies FAPESP, CNPq, CAPES, and of the German Academic Exchange Service (DAAD).

${ }^{1}$ C. S. Liang, J. M. Wu, and M. C. Chang, Appl. Phys. Lett. 81, 3624 (2002).

${ }^{2}$ H. N. Lee, D. Hesse, N. Zakharov, and U. Gôsele, Science 296, 2006 (2002).

${ }^{3}$ R. Ramesh and D. G. Schlom, Science 296, 1975 (2002).

${ }^{4}$ N. S. L. S. Vasconcelos, J. S. Vasconcelos, V. Bouquet, M. Guilloux-Viry, M. I. Bernardi, and J. A. Varela, Thin Solid Films 436, 213 (2003).

${ }^{5}$ A. Z. Simões, B. D. Stojanovic, A. Tangastev, N. Setter, and J. A. Varela, Integr. Ferroelectr. 43, 123 (2002).

${ }^{6}$ T. Takenaka and K. Sakata, Ferroelectrics 38, 769 (1981).

${ }^{7}$ S. B. Ren, C. J. Lu, J. S. Liu, H. M. Shen, and Y. N. Wang, Phys. Rev. B 54, R14337 (1996).

${ }^{8}$ M. Nagata, D. P. Vijay, X. B. Zhang, and S. B. Desu, Phys. Status Solidi A 157, 75 (1996).

${ }^{9}$ J. G. Simmons, Handbook of Thin-Film Technology, edited by L. I. Maissel and R. Glang (McGraw-Hill, New York, 1970), pp. 14-35.

${ }^{10}$ M. Sedlar and M. Sayer, Ceram. Int. 22, 241 (1996).

${ }^{11}$ N. Maffei and S. B. Krupanidhi, Appl. Phys. Lett. 60, 781 (1992).

${ }^{12}$ J. F. Scott, C. A. Araujo, B. M. Melnick, L. D. McMillan, and R. Zuleeg, J. Appl. Phys. 70, 382 (1991).

${ }^{13}$ J. Zhai and H. Chen, Appl. Phys. Lett. 82, 442 (2003).

${ }^{14}$ C. S. Hwang, B. T. Lee, C. S. Kang, J. W. Kim, K. H. Lee, H.-J. Cho, H. Horii, W. D. Kim, S. I. Lee, Y. B. Roh, and M. Y. Lee, J. Appl. Phys. 83, 3703 (1998).

${ }^{15}$ Y. Shimakawa, Y. Kubo Y. Tauchi, H. Asano, T. Kamiyama, F. Izumi, and Z. Hiroi, Appl. Phys. Lett. 79, 2791 (2001).

${ }^{16} \mathrm{H}$ N. Lee and D Hesse, Apnl. Phys. Lett 80,1040 (2002). 